\section{FASTER DIGITAL IMPRESSIONS, NOW WITH COLOUR}

The Planmeca FIT system for chairside digital impression dentistry provides clinics with a completely digital workflow from start to finish. It seamlessly integrates intraoral scanning, 3D designing and on-site milling into one software platform, allowing production of restorations in a single visit. Scanning is now 40\% faster than before, with colour scanning featured for the first time.

The Planmeca FIT system is all about integrated efficiency. Comprised of the PlanScan scanner, the PlanCAD Easy software and the PlanMill 40 milling unit, the system enables dental clinics to create high quality restorations, either choosing to perform the entire workflow in-house or flexibly outsource parts of it.

'Same day dentistry' has arrived.

To book your demonstra-

tion, get in touch with the

Planmeca team by calling 0500500 686, emailing marketing@planmeca. com or visit www. plandemo.co.uk.

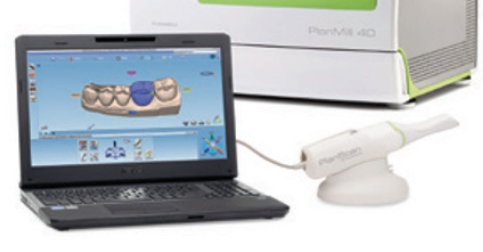

\section{TREATMENT OF THE WORN DENTITION}

Tooth wear is becoming an increasingly common problem in modern day dentistry and there are a large variety of conservative options available for treatment. However, this variety can also lead to confusion and apprehension. Making the right restorative decisions is a key to success.

Mizrahi Dental Teaching is offering a one day comprehensive course presented by Dr Basil Mizrahi that will discuss all aspect of the treatment of various types of tooth wear. It will be clinically oriented and delegates will come away feeling more confident and be able to implement what they have learnt into their clinical practice.

Topics covered will include:

- Veneers on worn teeth

- Dahl principle - when and how to use it

- Do you need to treat all the teeth?

- Crowns vs onlays on posterior teeth

- Increasing the VDO - how to decide when and by how much

- Posterior onlays - preparation design, material choice, how to bond them

- Palatal veneers

- Localised anterior wear $v s$ advanced generalised wear.

For more information on this and other upcoming courses visit www.mizrahi-dental-teaching.co.uk or call 02033942984.

\title{
HANDS-ON COURSES ON FIBRE TECHNOLOGY
}

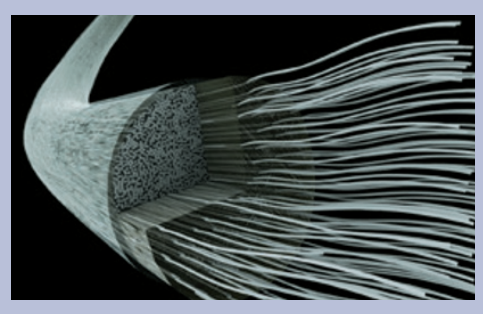

GC UK are supporting Fibrebond Ltd who are running hands-on courses up and down the country throughout 2016.

Offering six hours CPD, these comprehensive hands-on courses on fibre technology and aesthetic and functional composite restorations are presented by $\mathrm{Dr}$ Jansie Van Rensburg and Richard Newman RDT. The main aims and objectives are to introduce delegates to solutions for problems often experienced in dental surgeries and to provide practical information on how to manage them.

By the end of the course delegates should have a good knowledge and hands-on experience of composite restorations with a difference; alternative uses for composites; different matrix systems; how to overcome the big problem of open interproximal contacts and 'food trapping'; how to achieve a good marginal seal; and how to deal with subgingival cavities when delivering posterior composites; the layering technique, including characterisation and other brilliant tips to achieve the ultimate aesthetic result; 'gum shade' (pink aesthetics) including where, when and how to use them; the direct fibre reinforced composite bridge; how to place the fibre and build the pontic freehand; a demonstration of periodontal splinting; and a demonstration of anatomical fibre posts.

For further information contact Fibre Bond telephone 01424 755238 or 07783347423 or visit www.fibrebond.co.uk.

\section{GAIN VALUABLE EXPERIENCE IN LASER DENTISTRY}

Gain valuable experience in laser dentistry including advanced techniques in clinical and cosmetic procedures with various dental applications, such as decontamination techniques, ablation and therapy treatments.

See why you can no longer ignore lasers to help you and your patients. The British Institute of Laser Dentistry (BILD) training covers:

- Fundamentals of soft tissue laser technology

- Diode laser safety, legal and health requirements

- Procedural laser power settings

- Market and practise laser dentistry for profitability

- Learn techniques by practising on sheep head specimens.

Dr Anoop Maini is the lecturer and hands-on trainer assisted by Dr Daz Singh and Dr Ahmad Nounu.

What makes BILD stand out from other laser courses is the practical aspect, which allows dentists to leave the course and have the confidence to start using their laser straight away.

Furthermore at the hands-on seminar, Quicklase offer special deals for the attendees. Certification and six hours of CPD are also given.

Laser assisted dentistry has modernised dentistry and has become a vital part of the industry so don't miss out.

Call 01227780009 to book your place on the next course, 6 May 2016, in London. Spaces are limited.

www.bildentistry.com www.quicklase.com

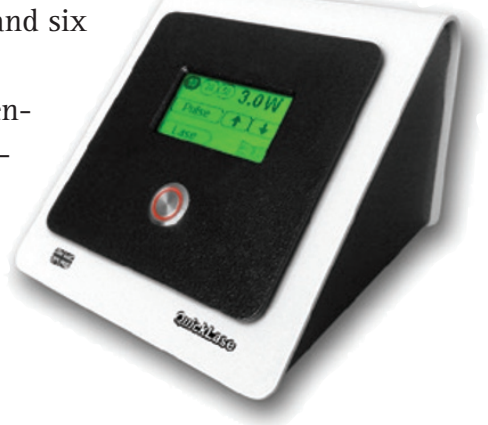

